\title{
Review
}

Carmen S.R. Freire*, Susana C.M. Fernandes, Armando J.D. Silvestre

and Carlos Pascoal Neto

\section{Novel cellulose-based composites based on nanofibrillated plant and bacterial cellulose: recent advances at the University of Aveiro - a review}

\begin{abstract}
The development of (nano)materials based on the renewable cellulose is a challenge. The present article provides a brief overview of the recent research efforts carried out at the CICECO Laboratory of the University of Aveiro on the development of novel composites based on nanofibrillated plant and bacterial cellulose embedded in natural and synthetic polymeric matrices such as poly(lactic acid), chitosan, starch, and pullulan. These materials have high potential for applications in packaging, paper coating, organic electronics, and biomedical products and devices.
\end{abstract}

Keywords: bacterial cellulose (BC), biopolymers, nanocomposites, nanofibers, nanofibrillated cellulose (NFC), plant cellulose, polysaccharides, renewable resources, transparent films

*Corresponding author: Carmen S.R. Freire, Department of Chemistry and CICECO, University of Aveiro, 3810-193 Aveiro, Portugal, e-mail: cfreire@ua.pt

Susana C.M. Fernandes, Armando J.D. Silvestre and

Carlos Pascoal Neto: Department of Chemistry and CICECO, University of Aveiro, 3810-193 Aveiro, Portugal

Susana C.M. Fernandes: Materials and Technologies' Group, Department of Chemical and Environmental Engineering, Polytechnic School, University of the Basque Country, Pza. Europa 1, 20018 Donostia-San Sebastian, Spain

\section{Introduction}

The finiteness of fossil raw materials led in the last decades to intense research activities toward a more sophisticated utilization of renewable materials, such as plant biomass (lignocellulosic feedstock), which are subsumed as "biorefinery" (Fernando et al. 2006; Kamm et al. 2006). The biorefinery concept is analogous to the traditional petroleum refinery, which means that biomass conversion processes should be improved so that more value-added chemicals can be produced aside from heat and power. The biorefinery concept is frequently developed in the context of the well-established pulping industry, with pulp (cellulose and hemicelluloses) as its main product and lignin as its byproduct. Also, the University of Aveiro met this rewarding challenge and dedicated intense research efforts to many aspects of wood chemistry, pulping, and bleaching technologies. Frequently, Eucalyptus globulus is in focus, a tree of large importance for pulp production in Portugal. Since the last decade, the biorefinery concept is an integrated part of the research efforts aiming at better utilization of important forest species of Portugal.

Concerning E. globulus, the research has been mainly devoted to high-value components from bark residues (Freire et al. 2002; Domingues et al. 2010; Santos et al. 2011) and to new applications of cellulose fibers (Freire et al. 2005, 2006a,b, 2008; Cunha et al. 2007a,b, 2010; Fernandes et al. 2011a; Tomé et al. 2011a).

The outstanding properties of cellulose fibers (Figure 1a and b) are well documented (Fengel and Wegener 1989; Klemm et al. 1998, 2005) in terms of mechanical strength, chemical behavior, biocompatibility, biodegradability, nontoxicity, absorption properties, and low density. These properties are the basis for novel applications beyond the well-established utilization in paper and textile products (Klemm et al. 2005).

Esterification, etherification, urethane formation, and cross-linking or graft copolymerization enlarge the application possibilities of cellulose (Klemm et al. 1998; Gandini 2008; Heinze and Petzold 2008; Yu and Chen 2009). A peculiarity is the controlled heterogeneous modification of cellulose fibers, where the reaction is limited to the most accessible regions of the fibers while its bulk mechanical properties are preserved. This is one of the strategies for utilization of cellulose as reinforcing elements in composites (Bledzki and Gassan 1999; Schurz 

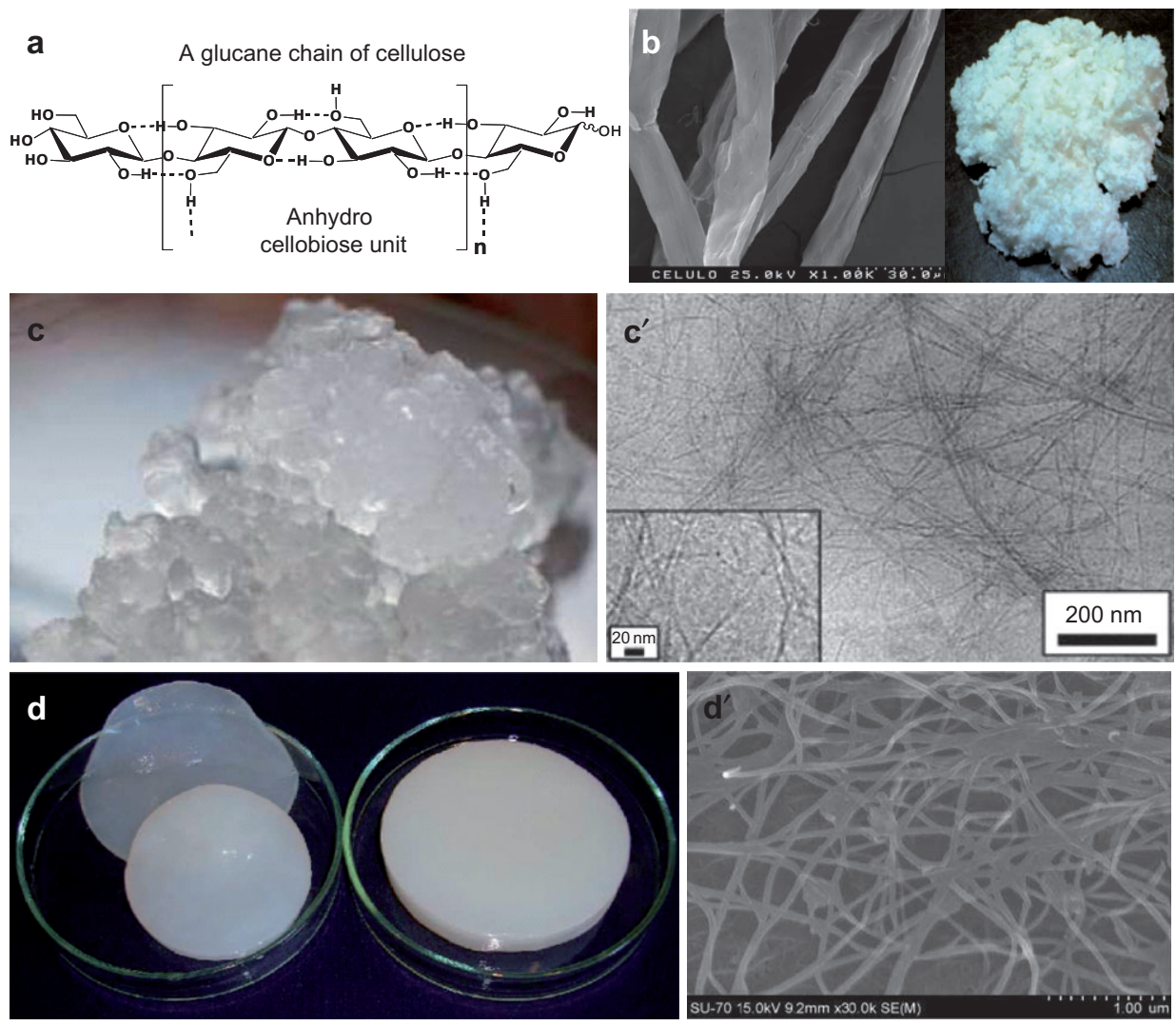

Figure 1 Images of cellulose.

(a) A glucan chain of cellulose with repeating anhydrocellobiose units. (b) Macroscopic and SEM images of conventional pulp fibers. (c and $c^{\prime}$ ) Macroscopic and SEM images of NFC. (d) Image of BC. (d') SEM image of BC.

1999; Mohanty et al. 2001; Belgacem and Gandini 2005; Samir et al. 2005; Freire and Gandini 2006; Teeri et al. 2007; Dufresne 2008). Here, cellulose replaces inorganic (mineral)-based fibers (Wang and Zhang 2009). Automotive, construction, and packaging are among the largest segments for these materials with an exponential growth in recent years.

More recently, polymer-based nanocomposites (multiphase materials) consisting of a polymer matrix and a nanofiller, gained particular attention and interest. They have very special properties in comparison with conventional polymer composites (Bordes et al. 2009), for example, improved mechanical, thermal, and barrier properties and transparency (Zimmermann et al. 2004; Hubbe et al. 2008; Nogi and Yano 2008; Azeredo 2009; Fukuzumi et al. 2009; Kim et al. 2009). The nanocomposites of this category, in which the micro- and nanofibrillated cellulose (MFC and NFC, respectively), cellulose whiskers, and bacterial cellulose (BC) play an essential role, have a wide range of application domain (Nakagaito and Yano 2004, 2005; Nakagaito et al. 2005; Shimazaki et al. 2007; Jung et al. 2008; Nogi et al. 2009).
The preparation, properties, modification, and application of NFC were reviewed extensively (Zimmermann et al. 2004; Samir et al. 2005; Hubbe et al. 2008; ChingaCarrasco 2011; Klemm et al. 2011; Petersen and Gatenholm 2011; Siqueira et al. 2011).

The first production of MFC from wood fibers was reported by Turbak et al. (1983). Meanwhile, the term NFC is more frequently applied. The disintegration of cellulose fibrils to nanocellulose is realized by highpressure homogenizers combined with chemical or enzymatic treatments (Preston 1974; Sjöström 1981; Klemm et al. 1998; Teeri et al. 2007). The obtained NFC suspensions (Figure 1c and $c^{\prime}$ ) bear the appearance of highly viscous shear-thinning transparent gels and have high aspect ratios and specific surface areas combined with remarkable strength and flexibility, low thermal expansion, high optical transparency, and specific barrier properties. MFC and NFC can be incorporated in different matrices such as hydroxypropylcellulose (Zimmermann et al. 2004), chitosan (CH; Nordqvist et al. 2007), viscous polysaccharide matrices in the form of 50/50 amylopectin-glycerol blends (Svagan et al. 2007), 
poly(lactic acid) (PLA; Iwatake et al. 2008; Suryanegara et al. 2009), polyvinyl alcohol (Zimmermann et al. 2004), and polyurethanes (Seydibeyoglu and Oksman 2008). The NFC-based nanocomposites are used for the production of transparent materials (Yano et al. 2005; Fukuzumi et al. 2009) and gas barrier films (Fukuzumi et al. 2009).

BC, also known as microbial cellulose, is produced by different bacteria genera, such as Gluconacetobacter, Sarcina, and Agrobacterium, but Gluconacetobacter xylinus is probably the most commonly referred strain in this context (Budhiono et al. 1999; Shoda and Sugano 2005; Pecoraro et al. 2008). Recently, it was reported by our group that $G$. sacchari also produces $\mathrm{BC}$ in very high yields (Trovatti et al. 2011). These bacteria are Gram-negative aerobic and nonphotosynthetic bacteria usually found in fruits, vegetables, vinegar, and alcoholic beverages. They are capable of converting several substrates into cellulose within a few days. Studied substrates comprise glucose, glycerol, and other organic materials, including residues from agroforest industries (Chawla et al. 2009; Carreira et al. 2011). BC can be produced as a highly swollen hydrogel and, depending on the static or agitated nature of the culture media, as a membrane (Figure $1 d$ and $d^{\prime}$ ) or in the form of small beads. BC consists of ribbons of microfibrils generated at the surface of the bacterial cell. The bacteria first segregate a structurally homogeneous slimy substance, and after a short time, the cellulose nanofibers are formed (Chawla et al. 2009). More precisely, BC is a threedimensional network consisting of nano- and microfibrils with the dimensions of 3-4 $\mathrm{nm}$ thickness and 70-80 nm length (Figure $1 d^{\prime}$ ), that is, the fibrils are approximately 1000 times thinner than typical plant cellulose fibrils. These dimensions explain the unique properties of BC. Additionally, BC is free of lignin, hemicelluloses, and other natural components usually associated with cellulose isolated from the cell wall of plants. BC has a high degree of polymerization and crystallinity, extremely high water holding capacity, high tensile strength, and high surface area (George et al. 2005a,b). BC is well suited as a reinforcing element in nanocomposites in several polymeric matrices, namely, cellulose acetate butyrate (Gindl and Keckes 2004), acrylic thermosetting resins (Yano et al. 2005; Ifuku et al. 2007), phenolic resins (Nakagaito et al. 2005), poly(ethylene oxide) (Brown and Laborie 2008), plasticized starch (Wan et al. 2009), PLA (Kim et al. 2009), and epoxidized soybean oil matrix (Retegi et al. 2012), just to mention a few examples.

Recent advances of nanocomposite research with NFC and $\mathrm{BC}$ as reinforcing elements achieved at the University of Aveiro will be reported in the next chapter.

\section{Research on cellulose nanocompos- ites at the University of Aveiro}

Different strategies were applied to obtain nanocomposites, namely, heterogeneous chemical modification, compounding with synthetic polymers matrices such as PLA, and blending with other natural polymers such as $\mathrm{CH}$, starch, and pullulan. Polysaccharide matrices are compatible with cellulose because of their structural similarity. This is the reason why simple "green procedures" such as casting of water-based suspensions or melting-mixing can be applied for the production of composites with polysaccharides and nanocellulose fibers. The next paragraphs will present some examples of these approaches.

\section{BC-PLA nanocomposites}

PLA is a versatile and biodegradable thermoplastic polyester (Figure 2a), which is produced entirely from renewable resources, specifically from starch-enriched raw materials such as sugar beet, corn, and wheat (Averous 2008). The properties of PLA such as high mechanical strength and stiffness, UV stability, and gloss open a large field of applications in the automotive industry, packaging, and medicine.

Nanocomposites with improved properties based on PLA matrix and BC were described by Tomé et al. (2011b), who prepared such materials by heterogeneous acetylation of BC followed by simple melting-mixing with PLA. The acetylation increases substantially the hydrophobicity of nanofibers and therefore their compatibility and adhesion with the PLA matrix. The compatibility was evidenced by scanning electron microscopy (SEM) images (Figure 2b').

PLA-BC nanocomposites have considerably improved mechanical properties as evidenced by the significant increase both in the storage modulus ( $\mathrm{E}^{\prime} / \mathrm{Pa}$; Figure $3 \mathrm{a}$ ) as well as Young's modulus and in the tensile strength (Tomé et al. 2011b). The increments were approximately $100 \%$, $40 \%$, and $25 \%$ for elastic modulus, Young's modulus, and tensile strength, respectively, even when the level of nanofiller loadings (up to 6\%) was low.

The incorporation of both unmodified and acetylated $\mathrm{BC}$ nanofibers in the PLA matrix also resulted in a considerable increase in the thermal properties of the corresponding nanocomposites (Figure $3 \mathrm{~b}$ ) and particularly those with acetylated BC fillers (PLA-BCAc), observed by the increment in both initial and maximum degradation temperatures, which reflect their excellent interfacial 

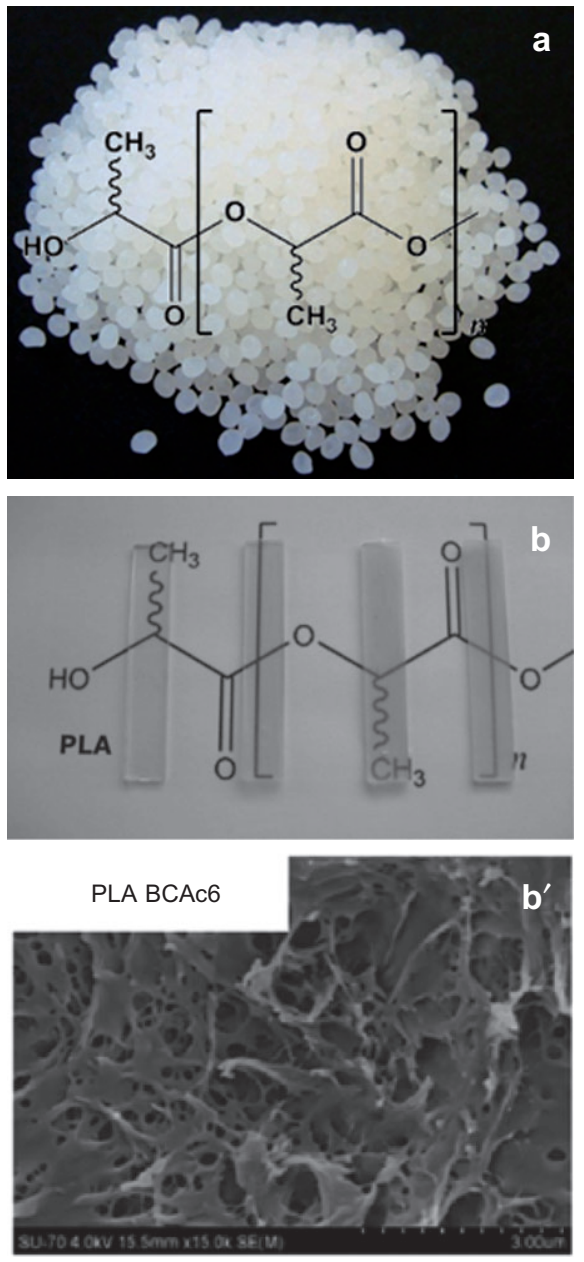

Figure 2 Images of PLA.

(a) Visual aspect of PLA pellets. ( $b$ and $b^{\prime}$ ) Optical and SEM images of PLA and PLA-BC nanocomposites (PLA-BC).

compatibility. For example, the incorporation of $6 \%$ of acetylated BC (PLA-BCAc6) elevated the initial and maximum degradation temperatures by $15^{\circ} \mathrm{C}$ and $14^{\circ} \mathrm{C}$, respectively.

Moreover, these nanocomposites also have a low hygroscopicity and considerable transparency (Figure 1b). For example, their transmittance (measured for specimens with a thickness of $\sim 1 \mathrm{~mm}$ ) at $580 \mathrm{~nm}$ was approximately 80\% for PLA, $70 \%$ for the nanocomposites prepared with PLA and $1 \%$ of acetylated BC (PLA-BCAc1), and $60 \%$ with $4 \%$ and $6 \%$ of acetylated BC (PLA-BCAc4 and PLA-BCAc6).

\section{$\mathrm{CH}$-nanocellulose transparent nanocomposites}

$\mathrm{CH}$ (Figure 4a), obtained from deacetylation of chitin, which is the main component of crustacean shells and insects' exoskeletons, is unique concerning a

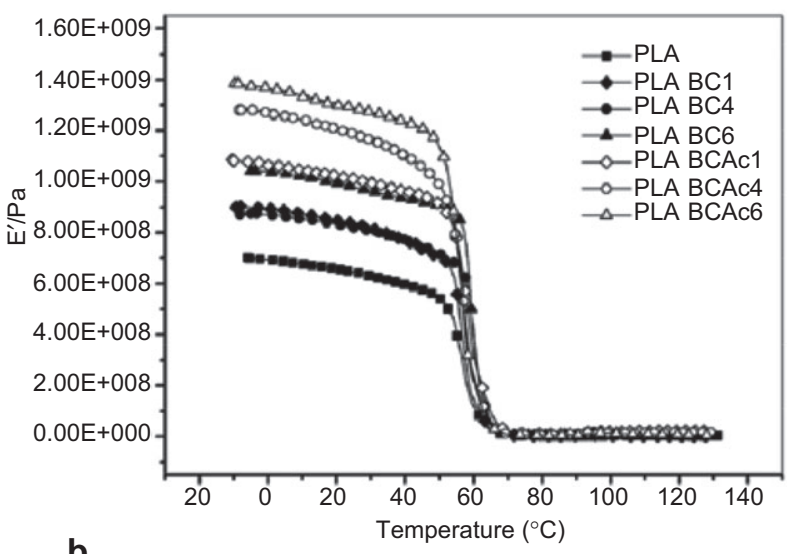

b

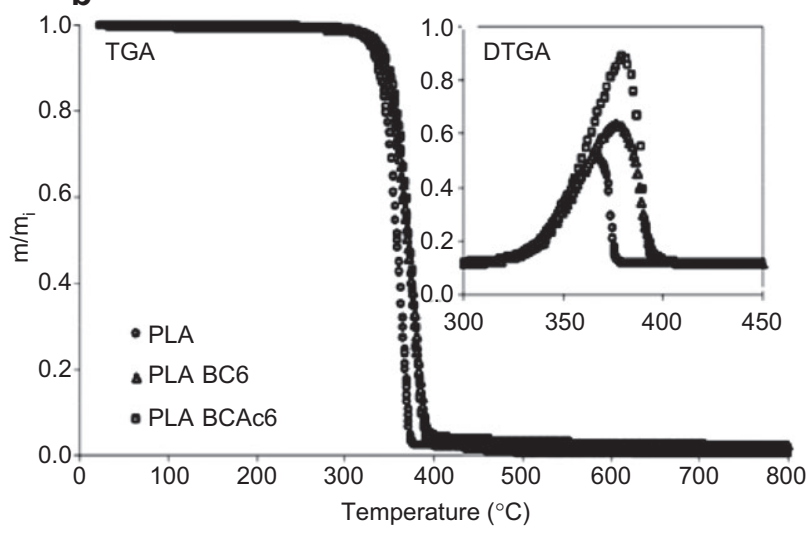

Figure 3 Properties of PLA and PLA-BC composites.

(a) Storage modulus of PLA and PLA-BC and PLA-BCAc acetylated (PLA-BCAc). (b) Thermogravimetric analysis and differential thermogravimetric analysis of PLA, PLA-BC, and PLA-BCAC.

biocompatibility, antimicrobial activity, biodegradability, and excellent film-forming ability (Rinaudo 2006; Peniche et al. 2008), which have attracted scientific and industrial interest in biotechnology, pharmaceutics, biomedicine, packaging, and wastewater treatment, among many other application fields. $\mathrm{CH}$ behaves in aqueous acidic media as a polycation contrasting with the other polysaccharides, which are usually neutral or anionic (Rinaudo 2006; Peniche et al. 2008).

The preparation and characterization of nanocomposite films (Figure $4 \mathrm{~b}$ and $\mathrm{c}$ ) were described based on different matrices of $\mathrm{CH}$ and BC (Fernandes et al. 2009, 2011b) or NFC (Fernandes et al. 2010, 2011b). The goal is the preparation of $\mathrm{CH}$ films with improved mechanical properties while keeping their transparency and thermal stability. The preparation was carried out by casting NFC or $\mathrm{BC}$ suspensions in aqueous $\mathrm{CH}$ (or chemically modified $\mathrm{CH})$. The components are perfectly compatible; moreover, $\mathrm{CH}$ solutions are an efficient media for stable suspensions of NFC or BC. As a result, the BC (as well as NFC) is very homogeneously distributed in the matrix (Figure $4 \mathrm{~b}$ 

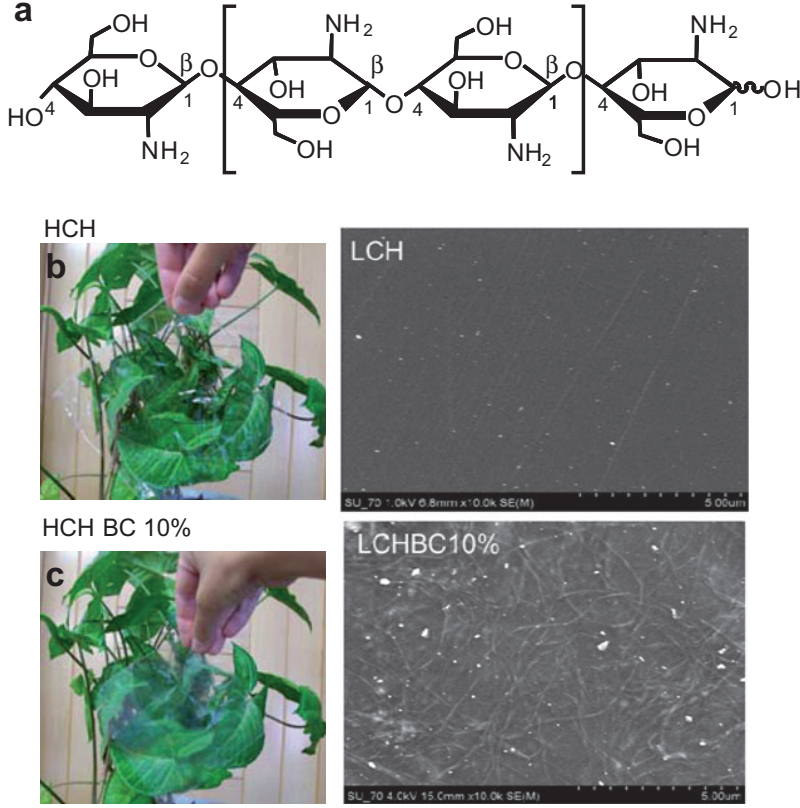

Figure 4 Images to $\mathrm{CH}$ and $\mathrm{CH}$-based composites.

(a) Chemical structure of a $\mathrm{CH}$ chain. (b) Illustration of the transparency of a CH film ( $\mathrm{HCH}$; left) and the SEM image of $\mathrm{LCH}$. (c) Illustration of the transparency of a $\mathrm{CH}-\mathrm{BC}$ nanocomposite $\mathrm{HCH}-\mathrm{BC} 10 \%$; left) and the SEM image of LCH-BC $10 \%$.

and c). The same figure demonstrates that the films are highly transparent and flexible. The mechanical properties of the films are manifested by excellent Young's modulus (that can go up to $320 \%$ improvement for some formulations) and tensile strength, and the thermal stability of the films is better compared with pure $\mathrm{CH}$ films.

These films are well suited for the development of transparent electronic devices, namely, organic fieldeffect transistors (Pereira et al. 2011). Finally, CH- and $\mathrm{BC}$-based aqueous formulations can be used successfully as surface coating of paper with substantially improved properties concerning the surface and printing quality and mechanical strength (Fernandes et al. 2011c).

\section{Pullulan-nanocellulose nanocomposites}

Pullulan is a linear water-soluble homopolysaccharide of glucose (Leathers 2003) consisting of maltotriose units that are integrated in the polymers by $\alpha-(1-6)$ linkages (Figure 5a). Pullulan is produced aerobically by certain strains of the polymorphic fungus Aureobasidium pullulans. It is able to form films that show high oxygen impermeability, nontoxicity, edibility, biodegradability, and compatibility to humans and the environment and have good mechanical properties (Krochta and DeMulder 1997). These films are a
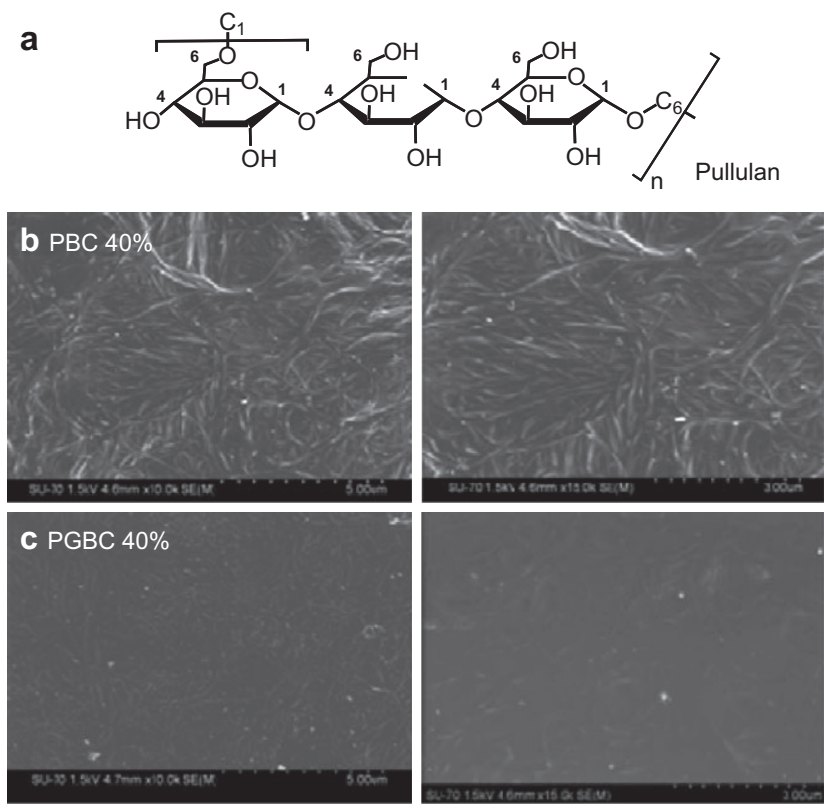

Figure 5 Images to pullulan and pullulan-based composites.

(a) Chemical structure of pullulan. Pullulan is a polysaccharide consisting of maltotriose units also known as $\alpha-1,4-; \alpha-1,6$-glucan. (b) SEM image of a PBC-based nacocomposite (PBC $40 \%$ ). (c) SEM image of a PBC-glycerol-based nanocomposite (PGBC 40\%).

normally used as coating or packaging materials for dried foods as well as in the pharmaceutical industry.

Novel pullulan-BC (PBC) nanocomposite films were prepared by Trovatti et al. (2012a) and the material was filled with 5\%, 10\%, 20\%, 40\%, and 60\% (w/w) BC and with glycerol as plasticizer. The procedure is similar to that described above for the $\mathrm{CH}$ nanocomposite films. The morphology of the nanocomposites was studied by SEM, aiming at the assessment of the dispersion of the $\mathrm{BC}$ nanofibrils into the pullulan matrix and the interfacial adhesion between the two components (Figure $5 b$ and c). As visible, the $\mathrm{BC}$ is well dispersed in the pullulan matrix, without forming considerable aggregates, even for high fiber contents (up to $40 \%$ ).

Figure 6 displays the stress-strain curves of nanocomposites made of pullulan, pullulan-glycerol (PG) films, $\mathrm{PBC}$, and PG-BC. The incorporation of $\mathrm{BC}$ into the pullulan matrix improves considerably both Young's modulus and tensile strength, with increments of up to $100 \%$ and 50\% for films without glycerol and up to $8000 \%$ and $7000 \%$ for films plasticized with glycerol. Glycerol as plasticizer increases the flexibility of the films, which is an important parameter in many applications.

The thermal stability of all PBC nanocomposites is considerably improved as a function of the $\mathrm{BC}$ content as evidenced by an increment in the degradation temperatures. 


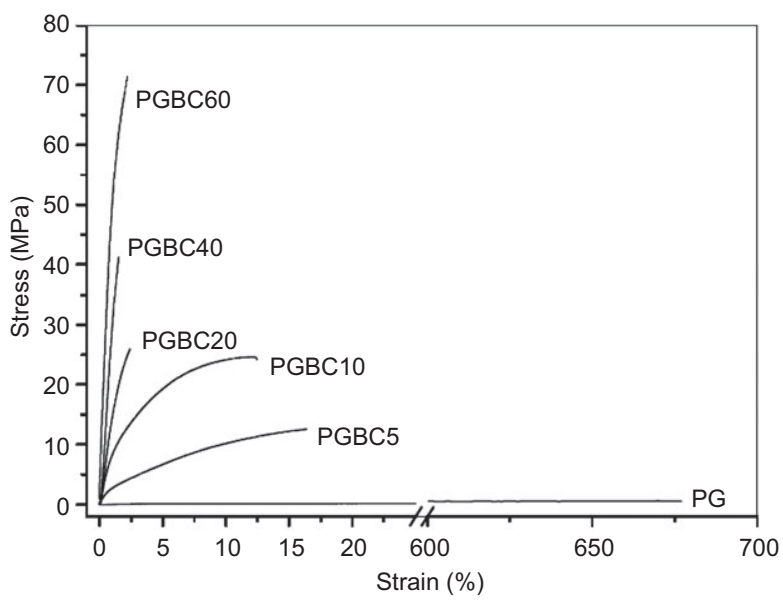

Figure 6 Stress-strain curves of PG and PG-BC nanocomposites (PGBC).

The numbers indicate the $\mathrm{BC}$ concentration in \%.

For instance, for $\mathrm{PBC}$ nanocomposites, the incorporation of $5 \% \mathrm{BC}$ resulted in an increase of approximately $3^{\circ} \mathrm{C}$ and $7^{\circ} \mathrm{C}$ in the initial and maximum degradation temperatures, respectively, whereas the incorporation of $20 \% \mathrm{BC}$ resulted in an increment of $9^{\circ} \mathrm{C}$ and $17^{\circ} \mathrm{C}$ of the initial and maximum degradation temperatures, respectively (Trovatti et al. 2012a).

Similar nanocomposites were also developed based on NFC as reinforcing element (Trovatti et al. 2012b). As in the case of the materials prepared with BC, all pullulan-NFC nanocomposites show a good homogeneity (atomic force microscopy images in Figure 7a and $\mathrm{a}^{\prime}$ ) and a high translucency as evidenced by the optical image of nanocomposite specimens against a printed background (Figure $7 \mathrm{~b}$ ). The image in the corner of Figure $7 \mathrm{~b}$ demonstrates the considerable flexibility of the films. Pullulan-NFC nanocomposites also showed considerable improvements in thermal stability, which means increments of up to $20^{\circ} \mathrm{C}$ in the degradation temperature (Trovatti et al. 2012b); finally, pullulan-NFC nanocomposites showed increments in mechanical properties of up to $5500 \%$ and $8000 \%$ in the Young's modulus and tensile strength, respectively, for films plasticized with glycerol when compared with the unfilled pullulan films (Trovatti et al. 2012b).

\section{Thermoplastic starch-cellulose nanocomposites}

Starch (Figure 8a) is one of the most abundant and available natural polysaccharides, which is well investigated as part of novel biocomposites. The disruption of the molecular chain interactions in starch granules (Figure 8b) leads to a thermoplastic material [thermoplastic starch (TPS)]
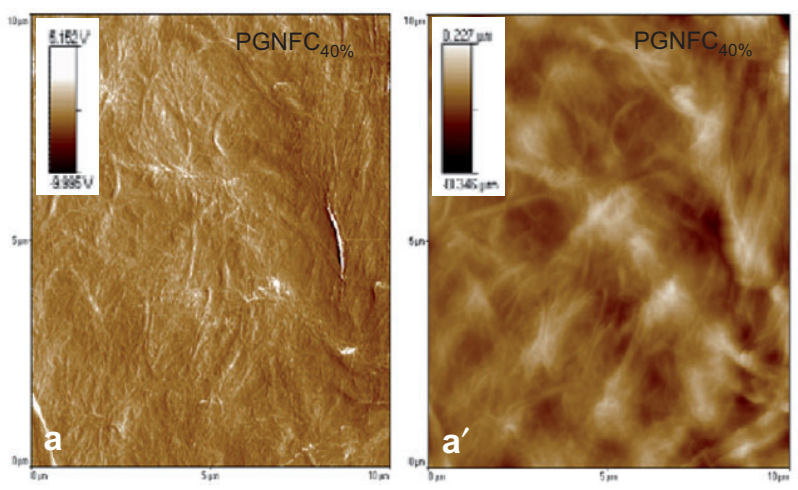

b

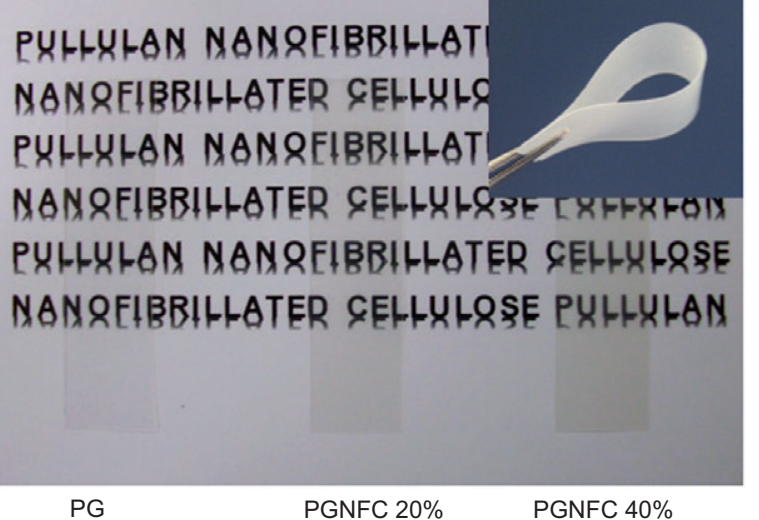

Figure 7 Images of nanocomposites based on pullulan and NFC (PNFC 40\%).

(a and $a^{\prime}$ ) Atomic force microscopy images of PNFC $40 \%$ with different enlargements. (b) Optical images to illustrate the transparency of films made of PG, PGNFC $20 \%$, and PGNFC $40 \%$. For abbreviations, see also Figure 5 .

under specific conditions and in the presence of a plasticizer, such as water or glycerol.

TPS composites are prepared in a single step with cornstarch by adding glycerol/water as plasticizer and $\mathrm{BC}(1 \%$ and $5 \%, \mathrm{w} / \mathrm{w})$ as reinforcing agent (Martins et al. 2009). The $B C$ is well dispersed in the matrix and there is a strong adhesion between BC and TPS (Figure 8c).

Plant NFC and especially BC proved to be efficient reinforcement agents even in low quantities. At 5\% BC loading, the Young's modulus and the tensile strength of the composite are elevated considerably (Figure 9a and b). The good performance of $\mathrm{BC}$ in comparison with plant NFC has to be emphasized (Figure 9a and b). This is probably due to the high aspect ratio and three-dimensional network of the BC.

In principle, these materials are promising in applications of food packaging and biodegradable materials. Then again, TPS-based materials are sensitive to humidity. The moisture sorption maximum was slightly reduced by the incorporation of BC. The interpretation is that starch is more hydrophilic than cellulose and nanofibers absorb 

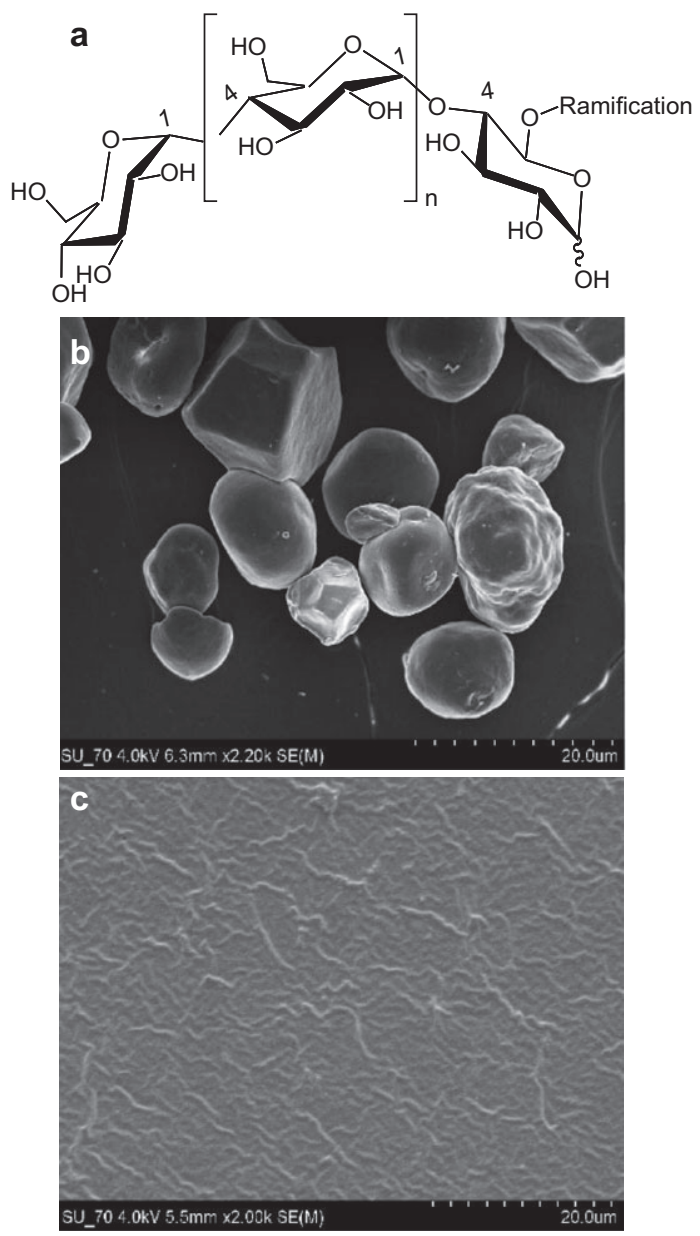

Figure 8 Starch and composites of starch.

(a) Segment of the chemical structure of a starch helix. (b) Starch granulates. (c) TPS film.

a part of the glycerol that will be not available to absorb humidity (Curvelo et al. 2001).

\section{Conclusions}

Novel composites based on nanofibrillated plant cellulose and $\mathrm{BC}$ embedded in natural and synthetic polymeric matrices such as PLA, $\mathrm{CH}$, starch, and pullulan are promising because of the high compatibility of the

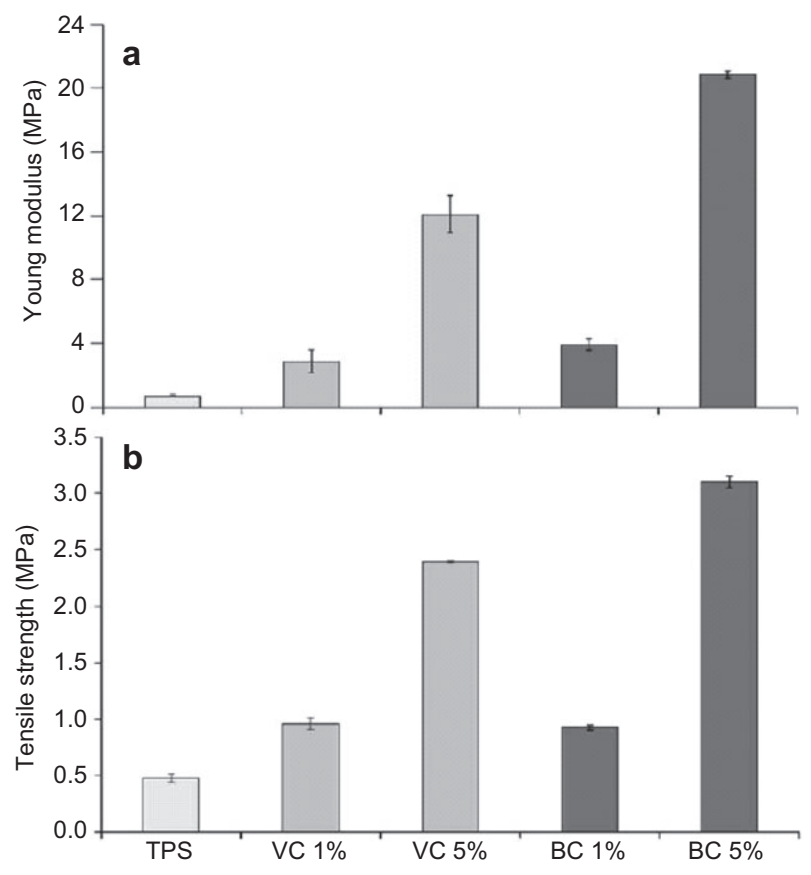

Figure 9 Properties of TPS and composites made of TPS reinforced with $1 \%$ and $5 \% \mathrm{BC}$ and plant cellulose (VC).

(a) Tensile strength. (b) Young's modulus.

enforcement and the matrix. The physical and thermal properties of these materials are unique, which predestine them for applications in packaging, electronic devices, and biomedicine. The family of these materials can be substantially widened by the combination with inorganic nanophases, a topic that has also been addressed by our group (Gonçalves et al. 2008, 2009; Pinto et al. 2008, 2009, 2012; Vilela et al. 2010). The development of cellulosebased nanocomposites is still a rewarding research field.

Acknowledgments: The authors thank CICECO (Pest-C/ CTM/LA0011/2011) for financial support and FCT for funding within the scope of the "National Program for Scientific Re-equipment” (Rede/1509/RME/2005 and REEQ/515/ $\mathrm{CTM} / 2005)$.

Received July 27, 2012; accepted November 13, 2012; previously published online December 18, 2012

\section{References}

Averous, L. (2008) Polylactic acid: synthesis, properties and applications. In: Monomers, Polymers and Composites From Renewable Resources. Eds. Belgacem, M.N., Gandini, A. Elsevier, London. pp. 433-450.

Azeredo, H.M.C. (2009) Nanocomposites for packaging applications. Food Res. Int. 42:1240-1253.
Belgacem, M.N., Gandini, A. (2005) The surface modification of cellulose fibres for use as reinforcing elements in composite materials. Compos. Interface 12:41-75.

Bledzki, A., Gassan, J. (1999) Composites reinforced with cellulose based fibres. Prog. Polym. Sci. 24:221-274. 
Bordes, P., Pollet, E., Averous, L. (2009) Nano-biocomposites: biodegradable polyester/nanoclay systems. Prog. Polym. Sci. 34:125-155.

Brown, E.E., Laborie, M.P.G. (2008) Bioengineering bacterial. cellulose/poly(ethylene oxide) nanocomposites. Biomacromolecules 9:3427-3428.

Budhiono, A., Rosidi, B., Taher, H., Iguchi, M. (1999) Kinetic aspects of bacterial cellulose formation in nata-de-coco culture system. Carbohydr. Polym. 40:137-143.

Carreira, P., Mendes, J.A.S., Trovatti, E., Serafim, L.S., Freire, C.S.R., Silvestre, A.J.D., Neto, C.P. (2011) Utilization of residues from agro-forest industries in the production of high value bacterial. cellulose. Bioresource Technol. 102:7354-7360.

Chawla, P.R., Bajaj, I.B., Survase, S.A., Singhal, R.S. (2009) Microbial cellulose: fermentative production and applications. Food Technol. Biotech. 47:107-124.

Chinga-Carrasco, G. (2011) Cellulose fibres, nanofibrils and microfibrils: the morphological sequence of MFC components from a plant physiology and fibre technology point of view. Nanoscale Res. Lett. 6:417.

Cunha, A.G., Freire, C.S.R., Silvestre, A.J.D., Neto, C.P., Gandini, A., Orblin, E., Fardim, P. (2007a) Characterization and evaluation of the hydrolytic stability of trifluoroacetylated cellulose fibers. J. Colloid Interface Sci. 316:360-366.

Cunha, A.G., Freire, C.S.R., Silvestre, A.J.D., Neto, C.P., Gandini, A., Orblin, E., Fardim, P. (2007b) Bi-phobic cellulose fibers derivatives via surface trifluoropropanoylation. Langmuir 23:10801-10806.

Cunha, A.G., Freire, C.S.R., Silvestre, A.J.D., Neto, C.P., Gandini, A. (2010) Preparation and characterization of novel highly. omniphobic cellulose fibers organic-inorganic hybrid. materials. Carbohydr. Polym. 80:1048-1056.

Curvelo, A.A.S., de Carvalho, A.J.F., Agnelli, J.A.M. (2001) Thermoplastic starch-cellulosic fibers composites: preliminary results. Carbohydr. Polym. 45:183-188.

Domingues, R.M.A., Sousa, G.D.A., Freire, C.S.R., Silvestre, A.J.D., Pascoal Neto, C. (2010) Eucalyptus globulus biomass residues from pulping industry as source of high value triterpenic compounds. Ind. Crops Prod. 31:65-70.

Dufresne, A. (2008) Cellulose-based composites and nanocomposites. In: Monomers, Polymers and Composites From Renewable Resources. Eds. Belgacem, M.N., Gandini, A. Elsevier, London. pp. 401-418.

Fengel, D., Wegener, G. Wood - Chemistry, Ultrastructure, Reactions. Walter de Gruyter, Berlin/New York, 1989.

Fernandes, S.C.M., Oliveira, L., Freire, C.S.R., Silvestre, A.J.D., Neto, C.P., Gandini, A., Desbrieres, J. (2009) Novel transparent. nanocomposite films based on chitosan and bacterial. cellulose. Green Chem. 11:2023-2029.

Fernandes, S.C.M., Freire, C.S.R., Silvestre, A.J.D., Neto, C.P., Gandini, A., Berglund, L.A., Salmén, L. (2010) Transparent chitosan films reinforced with a high content of nanofibrillated cellulose. Carbohydr. Polym. 81:394-401.

Fernandes, T.F., Trovatti, E., Freire, C.S.R., Silvestre, A.J.D., Neto, C.P., Gandini, A., Sadocco, P. (2011a) Preparation and. characterization of novel biodegradable composites based on acylated cellulose fibers and poly(ethylene sebacate). Compos. Sci. Technol. 71:1908-1913.

Fernandes, S.C.M., Freire, C.S.R. Silvestre, A.J.D., Neto, C.P., Gandini, A. (2011b) Novel materials based on chitosan and. cellulose. Polym. Int. 60:875-882.
Fernandes, S.C.M., Freire, C.S.R., Silvestre, A.J.D., Pascoal Neto, C., Gandini, A. (2011c) Aqueous coating compositions for use in surface treatment of cellulosic substrates. Patent: W02011/012934A2.

Fernando, S., Adhikari, S., Chandrapal, C., Murali, N. (2006) Biorefineries: current status, challenges, and future direction. Energy Fuels 20:1727-1737.

Freire, C.S.R., Gandini, A. (2006) Recent advances in the controlled heterogeneous modification of cellulose for the development of novel materials. Cell. Chem. Technol. 40:691-698.

Freire, C.S.R., Silvestre, A.J.D., Pascoal Neto, C., Cavaleiro, J.A.S. (2002) Lipophilic extractives of the inner and outer bark of Eucalyptus globulus. Holzforschung 56:372-379.

Freire, C.S.R., Silvestre, A.J.D., Neto, C.P., Rocha, R.M.A. (2005) An efficient method for determination of the degree of substitution of cellulose esters of long chain aliphatic acids. Cellulose 12:449-458.

Freire, C.S.R., Silvestre, A.J.D., Neto, C.P., Belgacem, M.N., Gandini, A. (2006a) Controlled heterogeneous modification of cellulose fibers with fatty acids: effect of reaction conditions on the extent of esterification and fiber properties. J. Appl. Polym. Sci. 100:1093-1102.

Freire, C.S.R., Silvestre, A.J.D., Neto, C.P., Gandini, A., Fardim, P., Holmbom, B. (2006b) Surface characterization by XPS, contact angle measurements and ToF-SIMS of cellulose fibers partially esterified with fatty acids. J. Colloid Interface Sci. 301:205-209.

Freire, C.S.R., Silvestre, A.J.D., Neto, C.P., Gandini, A., Martin, L., Mondragon, I. (2008) Composites based on acylated cellulose fibers and low-density polyethylene. Effect of the fiber content, degree of substitution and fatty acid chain length on final properties. Compos. Sci. Technol. 68:3358-3364.

Fukuzumi, H., Saito, T., Wata, T., Kumamoto, Y., Isogai, A. (2009) Transparent and high gas barrier films of cellulose nanofibers prepared by TEMPO-mediated oxidation. Biomacromolecules 10:162-165.

Gandini, A. (2008) Polymers from renewable resources: a challenge for the future of macromolecular materials. Macromolecules 41:9491-9504.

George, J., Ramana, K.V., Sabapathy, S.N., Bawa, A.S. (2005a) Physico-mechanical properties of chemically treated bacterial (Acetobacter xylinum) cellulose membrane. World J. Microb. Biot. 21:1323-1327.

George, J., Ramana, K.V., Sabapathy, S.N., Jagannath, J.H. Bawa, A.S. (2005b) Characterization of chemically treated bacterial (Acetobacter xylinum) biopolymer: some thermo-mechanical properties. Int. J. Biol. Macromol. 37:189-194.

Gindl, W., Keckes, J. (2004) Tensile properties of cellulose acetate butyrate composites reinforced with bacterial cellulose. Compos. Sci. Technol. 64:2407-2413.

Gonçalves, G., Marques, P.A.A.P., Trindade, T., Neto, C.P., Gandini, A. (2008) Superhydrophobic cellulose nanocomposites. J. Colloid Interf. Sci. 324:42-46.

Gonçalves, G., Marques, P.A.A.P., Neto, C. P., Trindade, T., Peres, M., Monteiro, T. (2009) Growth, structural, and optical characterization of $\mathrm{ZnO}$-coated cellulosic fibers. Cryst. Growth Des. 9:386-390.

Heinze, T., Petzold, K. (2008) Cellulose chemistry: novel products and synthesis paths. In: Monomers, Polymers and Composites From Renewable Resources. Eds. Belgacem, M.N., Gandini, A. Elsevier, London. pp. 43-368. 
Hubbe, M.A., Rojas, O.J., Lucia, A.L., Sain, M. (2008) Cellulosic nanocomposites: a review. Bioresources 3:929-980.

Ifuku, S., Nogi, M., Abe, K., Handa, K., Nakatsubo F., Yano, H. (2007) Surface modification of bacterial cellulose nanofibers for property enhancement of optically transparent composites. Dependence on acetyl-group DS. Biomacromolecules 8:1973-1978.

Iwatake, A., Nogi, M., Yano, H. (2008) Cellulose nanofiber-reinforced polylactic acid. Compos. Sci. Technol. 68:2103-2106.

Jung, R., Kim, H.S., Kim, Y., Kwon, S.M., Lee, H.S., In, H.J. (2008) Electrically conductive transparent papers using multiwalled carbon nanotubes. J. Polym. Sci. Pol. Phys. 46:1235-1242.

Kamm, B., Gruber, P.R., Kamm, M. Biorefineries - Industrial Processes and Products. Wiley-VCH, Weinheim, Germany, 2006.

Kim, Y., Jung, R., Kim, H.S., Jin, H.J. (2009) Transparent nanocomposites prepared by incorporating microbial nanofibrils into poly(L-lactic acid). Curr. Appl. Phys. 9:S69-S71.

Klemm, D., Heinze, T., Wagenknecht, W. Comprehensive Cellulose Chemistry. Wiley-VCH, Weinheim, Germany, 1998.

Klemm, D., Heublein, B., Fink, H.P., Bohn, A. (2005) Cellulose: fascinating biopolymer and sustainable raw material. Angew. Chem. Int. Ed. 30:3358-3393.

Klemm, D., Kramer, F., Moritz, S., Lindstrom, T., Ankerfors, M., Gray, D., Dorris, A. (2011) Nanocelluloses: a new family of nature-based materials. Angew. Chem. Int. Ed. 50:5438-5466.

Krochta, J.M., DeMulder, C. (1997) Edible and biodegradable polymer films: challenges and opportunities. Food Technol. Chic. 51:61-74.

Leathers, T.D. (2003) Biotechnological production and applications of pullulan. Appl. Microbiol. Biotechnol. 62:468-473.

Martins, I.M.G., Magina, S.P., Oliveira, L., Freire, C.S.R., Silvestre, A.J.D., Neto, C.P., Gandini, A. (2009) New biocomposites based on thermoplastic starch and bacterial cellulose. Compos. Sci. Technol. 69:2724-2733.

Mohanty, A.K., Misra, M., Drzal, L.T. (2001) Surface modification of natural fibers and performance of resulting biocomposites: an overview. Compos. Interface 8:313-343.

Nakagaito, A.N., Yano, H. (2004) The effect of morphological changes from pulp fiber towards nano-scale fibrillated cellulose on the mechanical properties of high-strength plant fiber based composites. Appl. Phys. A Mater. 78:547-552.

Nakagaito, A.N., Yano, H. (2005) Novel high-strength biocomposites based on microfibrillated cellulose having nanoorder-unit web-like network structure. Appl. Phys. A Mater. 80:155-159.

Nakagaito, A.N., Iwamoto, S., Yano, H. (2005) Bacterial cellulose: the ultimate nano-scalar cellulose morphology for the production of high-strength composites. Appl. Phys. A Mater. 80:93-97.

Nogi, M., Yano, H. (2008) Transparent nanocomposites based on cellulose produced by bacteria offer potential innovation in the electronics device industry. Adv. Mater. 20:1849-1852.

Nogi, M., Iwamoto, S., Nakagaito, A.N., Yano, H. (2009) Optically transparent nanofiber paper. Adv. Mater. 21:1595-1598.

Nordqvist, D., Idermark, J., Hedenqvist, M., Gällstedt, M., Ankerfors, M., Lindström, T. (2007) Enhancement of the wet properties of transparent chitosan-acetic acid-salt films using microfibrillated cellulose. Biomacromolecules 8:2398-2403.

Pecoraro, E., Manzani, D., Messaddeq, Y., Ribeiro, S.J.L. (2008) Bacterial cellulose from Glucanacetobacter xylinus: preparation, properties and applications. In: Monomers, Polymers and Composites From Renewable Resources. Eds. Belgacem, M.N., Gandini, A. Elsevier, London. pp. 369-383.
Peniche, C., Argüelles-Monal, W., Goycoolea, F.M. (2008) Chitin and chitosan: major sources, properties and applications. In: Monomers, Polymers and Composites From Renewable Resources. Eds. Belgacem, M.N., Gandini, A. Elsevier, London. pp. 517-542.

Pereira, A.T., Ferreira, Q., Pecoraro, E., Freire, C.S.R., Pascoal Neto, C., Silvestre, A.J.D., Trovatti, E., Fernandes, S.C.M., Morgado, J., Alcacer L. (2011) Inkject printing of organic field-effect transistors using biocellulose derivative materials. XXII Meeting of the Portuguese Chemical Society, Oporto, Portugal, July 2011.

Petersen, N., Gatenholm, P. (2011) Bacterial cellulose-based materials and medical devices: current state and perspectives. Appl. Microbiol. Biotechnol. 91:1277-1286.

Pinto, R.J.B., Marques, P.A.A.P., Barros-Timmons, A.M., Trindade, T., Neto, C.P. (2008) Novel $\mathrm{SiO}_{2} /$ cellulose nanocomposites obtained by in situ synthesis and via polyelectrolytes assembly. Compos Sci. Technol. 68:1088-1093.

Pinto, R.J.B., Marques, P.A.A.P., Neto, C.P., Trindade, T., Daina, S., Sadocco, P. (2009) Antibacterial activity of nanocomposites of silver and bacterial or vegetable cellulosic fibers. Acta Biomater. 5:2279-2289.

Pinto, R.J.B., Fernandes, S.C.M., Freire, C.S.R., Sadocco, P., Causio, J., Neto, C.P., Trindade, T. (2012) Antibacterial activity of optically transparent nanocomposite films based on chitosan or its derivatives and silver nanoparticles. Carbohydr. Res. 348:77-83.

Preston, R.D. The Physical Biology of the Plant Cell Wall. Chapman and Hall, London, 1974.

Retegi, A., Algar, I., Martin, L., Altuna, F., Stefani, P., Zuluaga, R., Gañán, P., Mondragon, I. (2012) Sustainable optically transparent composites based on epoxidized soy-bean oil (ESO) matrix and high contents of bacterial cellulose (BC). Cellulose 19:103-109.

Rinaudo, M. (2006) Chitin and chitosan: properties and applications. Prog. Polym. Sci. 31:603-632.

Samir, M.A.S.A., Alloin, F., Dufresne, A. (2005) Review of recent research into cellulosic whiskers: their properties and their application in nanocomposite field. Biomacromolecules 6:612-626.

Santos, S.A.O., Freire, C.S.R., Domingues, M.R., Silvestre, A.J.D., Neto, C.P. (2011) Characterization of phenolic components in polar extracts of Eucalyptus globulus Labill. bark by high performance liquid chromatography mass spectrometry. J. Agric. Food Chem. 59:9386-9393.

Schurz, J. (1999) Trends in polymer science: a bright future for cellulose. Prog. Polym. Sci. 24:481-483.

Seydibeyoglu, M.O., Oksman, K. (2008) Novel nanocomposites based on polyurethane and micro fibrillated cellulose. Compos. Sci. Technol. 68:908-914.

Shimazaki, Y., Miyazaki, Y., Takezawa, Y., Nogi, M., Abe, K., Ifuku, S., Yano, H. (2007) Excellent thermal conductivity of transparent cellulose nanofiber/epoxy resin nanocomposites. Biomacromolecules 8:2976-2978.

Shoda, M., Sugano, Y. (2005) Recent advances in bacterial cellulose production. Biotechnol. Bioprocess Eng. 10:1-8.

Siqueira, G., Bras, J., Dufresne, A. (2011) Cellulose whiskers versus microfibrils: influence of the nature of the nanoparticle and its surface functionalization on the thermal and mechanical properties of nanocomposites. Biomacromolecules 10:425-432. 
Sjöström, E. Wood Chemistry - Fundamentals and Applications. Academic Press, USA, 1981.

Suryanegara, L., Nakagaito, A., Yano, H. (2009) The effect of crystallization of PLA on the thermal and mechanical properties of microfibrillated cellulose-reinforced PLA composites. Compos. Sci. Technol. 69:1187-1192.

Svagan, A.J., Samir, M.A.S.A, Berglund, L.A. (2007) Biomimetic polysaccharide nanocomposites of high cellulose content and high toughness. Biomacromolecules 8:2556-2563.

Teeri, T.T., Brumer III, H., Daniel, G., Gatenholm, P (2007) Biomimetic engineering of cellulose-based materials. Trends Biotechnol. 25:299-306.

Tomé, L.C., Freire, M.G., Rebelo, L.P.N., Silvestre, A.J.D., Neto, C.P., Marrucho, I.M., Freire, C.S.R. (2011a) Surface hydrophobization of bacterial and vegetable cellulose fibers using ionic liquids as solvent media and catalysts. Green Chem. 13:2464-2470.

Tomé, L.C., Pinto, R.J.B., Trovatti, E., Freire, C.S.R., Silvestre, A.J.D., Neto, C.P., Gandini, A. (2011b) Transparent bionanocomposites with improved properties prepared from acetylated bacterial cellulose and poly(lactic acid) through a simple approach. Green Chem. 13:419-427.

Trovatti, E., Serafim, L.S., Freire, C.S.R., Silvestre, A.J.D., Neto, C.P. (2011) Gluconacetobacter sacchari: an efficient bacterial cellulose cell-factory. Carbohydr. Polym. 86:1417-1420.

Trovatti, E., Fernandes, S.C.M., Rubatat, L., Freire, C.S.R., Silvestre, A.J.D., Neto, C.P. (2012a) Sustainable nanocomposite films based on bacterial cellulose and pullulan. Cellulose 19:729-737.

Trovatti, E., Fernandes, S.C.M., Rubatat, L., Perez, D.S., Freire, C.S.R., Silvestre, A.J.D., Neto, C.P. (2012b) Pullulan-nanofibrillated cellulose composite films with improved thermal and mechanical properties. Compos. Sci. Technol. 72:1556-1561.

Turbak, A.F., Snyder, F.W., Sandberg, K.R. (1983) Microfibrillated cellulose. J. Appl. Polym. Sci. 37:815-827.

Vilela, C., Freire, C.S.R., Marques, P.A.A.P., Trindade, T., Neto, C.P., Fardim, P. (2010) Synthesis and characterization of new $\mathrm{CaCO}_{3} /$ cellulose nanocomposites prepared by controlled hydrolysis of dimethylcarbonate. Carbohydr. Polym. 79:1150-1156.

Wan, Y.Z., Luo, H.L., He, F., Liang, H., Huang, Y., Li, X.L. (2009) Mechanical, moisture absorption, and biodegradation behaviors of bacterial cellulose fibre-reinforced starch biocomposites. Compos. Sci. Technol. 69:1212-1217.

Wang, Y., Zhang, L. Biodegradable Polymer Blends and Composites From Renewable Resources. Wiley, New Jersey, 2009.

Yano, H., Sugiyama, J., Nakagaito, A.N., Nogi, M., Matsuura, T., Hikita M., Handa, K. (2005) Optically transparent composites reinforced with networks of bacterial nanofibres. Adv. Mater. 17:153-155.

Yu, L., Chen, L. Biodegradable Polymer Blends and Composites From Renewable Resources. Wiley \& Sons, New Jersey, 2009.

Zimmermann, T., Pöhler, E., Geiger, T. (2004) Cellulose fibrils for polymer reinforcement. Adv. Eng. Mater. 6:754-761. 